\title{
Thyroglossal duct cysts: clinicoradiological diagnosis and outcome of surgery
}

\section{Original Article}

\author{
Ahmed Gaber Hassanein ${ }^{a, b}$ and Fahd A. Qahtanic \\ ${ }^{a}$ Maxillofacial Surgery Unit, Department of General Surgery, Sohag Faculty of Medicine, \\ Sohag University, Sohag, Egypt, ${ }^{b}$ Department of Maxillofacial Surgery, Faculty of Dentistry \\ and 'Department of Vascular, Neuro and Interventional Radiology, Faculty of Medicine, Al- \\ Baha University, Kingdom of Saudi Arabia.
}

\begin{abstract}
Introduction: Thyroglossal duct cyst (TGDC) is a congenital malformation caused by failure of obliteration of the thyroglossal duct. It presents at any age and often requires surgical excision. This study was done to study our cases of TGDC to get some conclusions that may help the management of such cases.

Patients and Methods: This is a prospective study done at the Maxillofacial Surgery Unit, General Surgery Department, Sohag University Hospital, Sohag, Egypt in collaboration with Vascular, Neuro and Interventional Radiology Departments, Faculty of Medicine, Al-Baha University, Kingdom of Saudi Arabia. It included patients with the diagnosis of TGDC who were managed between July 2011 and June 2017. Their charts were reviewed for the demographics, clinical presentations, radiological investigations, management, and outcome.

Results: The study included 60 patients; 41 (68.3\%) men and 19 (26.7\%) women. The age of the patients ranged between 2 and 29 years; 45 (75\%) patients were under 10 years. The complaint was neck mass in $49(81.6 \%)$ patients, discharging opening in $11(18.4 \%)$ patients. All cases were primary cases. The cyst or fistula opening was located adjacent to the hyoid bone in $51(85 \%)$ patients, infrahyoid in seven (11.7\%) patients, and suprahyoid in two $(3.3 \%)$ patients. Neck ultrasonography in all patients detected the cyst and its location and assured that the thyroid gland was present in its normal location. These patients were treated by the classical Sistrunk procedure. The follow-up period ranged between 3 and 30 weeks. One patient had recurrence and operated on 1 year later.

Conclusion: TGDC is the most common cervical congenital anomaly. It can be found in all age groups, with the highest incidence in pediatric males. Although, it is diagnosed clinically in most of the cases, the use of radiological investigations can improve the diagnosis. The knowledge of embryology, meticulous dissection along anatomical planes, and excision of the core of the hyoid bone is essential to decrease recurrence of TGDC.
\end{abstract}

Received: $20^{\text {th }}$ November, 2017, Accepted: $20^{\text {th }}$ December, 2017.

Key Words: fistula, Sistrunk procedure, thyroglossal duct cyst

Corresponding Author: Ahmed Gaber Hassanein, MD, Department of General Surgery, Sohag Faculty of Medicine, Sohag University, Sohag, Egypt

Tel.: + 20115765 1422, E-mail: ahmedgaber_74@yahoo.com

ISSN: 2090-097X, January, Vol. 9, No. 1.

\section{INTRODUCTION}

Thyroglossal duct cyst (TGDC) is the most common developmental cyst of the cervical region. It arises in about $7 \%$ of the population [1] and accounts for $70 \%$ of congenital neck abnormalities [2].

It is a fibrous cystic swelling that results from failure of obliteration of the embryological TGDC at eighth gestational week. The duct runs from the foramen cecum and the anatomical resting place of the thyroid, anterior to the upper trachea, passing through or around the hyoid bone. Therefore, a TGDC may form at any point along the duct with the majority forming around the level of the hyoid bone [3].

TGDCs usually present in young children, although they may be detected in patients of any age [4-6]. The most common clinical presentation is a gradually enlarging painless mass in the midline of the neck with a diameter usually in the range of 2-4 cm. It can also present as a fistula which occurs when the TGDC is infected and is drained surgically or spontaneously [6]. 
On physical examination, the mass typically is located at the midline of the anterior neck and moves upward with protrusion of the tongue. In most cases, a careful history taking and clinical examination are adequate to establish accurate preoperative diagnosis.

Imaging studies are important to confirm the diagnosis, identify the presence of functioning thyroid tissue in the neck, and to plan an appropriate treatment strategy. Ultrasound (US) is the most common study used to evaluate midline neck lesions in children. It can distinguish TGDC from other common lesions such as lymph nodes or dermoid cysts [7]. Oyewumi et al. [8] suggested three clinically dependable US features that were helpful in differentiating TGDC from a dermoid cyst [8]. Although computed tomography (CT) and MRI can be utilized for the diagnosis of TGDC, US is the most commonly used basic imaging technique, because it is easily accessible, it does not involve radiation, and it confers superior nearfield resolution [9-11]. Uncomplicated TGDC on US is described as being thin-walled anechoic structures [12] and as being heterogeneous with a thick wall if they have been infected or hypoechoic in the presence of hemorrhage [13].

The differential diagnosis with other anterior midline neck nodular lesions is important because management is different for every lesion [14]. The differentiation between a TGDC and a lymph node or a dermoid cyst may not be simple, particularly when the TGDC does not present as a thin-walled, anechoic cyst, central and in close relation to the strap muscles. When the TGDC presents with these criteria, a dermoid cyst should be excluded [8].

Earlier, the treatment of TGDC was simple excision or incision and drainage, which yielded a high recurrence rate of 50\%. In 1893, Schlang [15] introduced the excision of the cyst along with the central part of the hyoid bone, which decreased the recurrence rate to $20 \%$. In 1920 , Sistrunk [16] advocated his technique for the treatment of TGDC in which a segment of the hyoid bone is removed with meticulous excision of the persistent duct up to the foramen cecum. Studies reported that Sistrunk has reduced the recurrence from 50 to $3 \%$ [17].

Various studies have been done on TGDC to understand its varied presentation, diagnosis, and treatment outcome. Hence, the purpose behind this work was to analyze the presentation, the diagnostic value of US, and the approach to management in patients with TGDC.

\section{PATIENTS AND METHODS}

This is a prospective study done at the Maxillofacial Surgery Unit, General Surgery Department, Sohag University Hospital, Sohag, Egypt, in collaboration with Vascular, Neuro and Interventional Radiology Departments,
Faculty of Medicine, Al-Baha University, Kingdom of Saudi Arabia. It included 60 consecutive patients with the diagnosis of TGDC who were managed between July 2011 and June 2017. This study was conducted after approval by the Institutional Human Research and Ethics Committees.

Informed consent regarding surgery and inclusion in the study was signed by the patient if he was an adult or by his parent or legal guardian in case of being below the age of 18 years.

\section{INCLUSION CRITERIA}

All primary cases with anterior neck mass and/or discharging opening with the clinical diagnosis of TGDC and/or fistula during the study period and signed an informed consent to be enrolled in this research.

\section{EXCLUSION CRITERIA}

1. Cases with anterior neck mass and/or dischargin opening which were not clinically diagnosed as TGDC and/or fistula.

\section{Recurrent cases.}

3. Refusal to be enrolled in the study.

The details of each case were recorded using a pro forma. These included the following data: age at presentation, sex, clinical characteristics of presentation, location of the cyst, duration of complaint, imaging study, clinical diagnosis, surgical procedures, surgical complications, histopathologic diagnosis, duration of follow-up, and complications.

A high-frequency linear probe was used to perform US examinations; the patients were laid supine, with neck extension. Serial transverse and longitudinal US images of the lesions were acquired. The following US features were evaluated:

1. Location in relation to the midline (midline vs. offmidline).

2. Level in relation to the hyoid bone (suprahyoid, juxtahyoid, or infrahyoid). If the lower margin of the cyst was above the hyoid bone, the cyst was defined as a suprahyoid cyst. On the other hand, if the upper margin of the cyst was below the hyoid bone, it was defined as an infrahyoid cyst.

\section{STATISTICAL METHODS}

The results were statistically analyzed using SPSS for Windows (SPSS Inc., Chicago, Illinois, USA). 


\section{RESULTS}

There were $41(68.3 \%)$ men and $19(26.7 \%)$ women. The age ranged between 2 and 29 years with a mean age of 11.18 years and the median age was 9 years. Fortyfive $(75 \%)$ of them were under 10 years, $11(18.3 \%)$ were between 10 and 20 years, and four $(6.7 \%)$ were aged above 20 years (Table 1 ).

Table 1: Demographic, clinical, and radiological data of the patients and the outcome of surgery

\begin{tabular}{|c|c|}
\hline Freque & ncy $(\%)$ \\
\hline \multicolumn{2}{|l|}{ Sex } \\
\hline Male & $41(68.3)$ \\
\hline Female & $19(26.7)$ \\
\hline \multicolumn{2}{|l|}{ Age } \\
\hline Below 10 & $45(75)$ \\
\hline From 10 to 20 & $11(18.3)$ \\
\hline Above 20 & $4(6.7)$ \\
\hline \multicolumn{2}{|l|}{ Chief complaint } \\
\hline Neck mass & $49(81.6)$ \\
\hline Discharging opening & $7(11.7)$ \\
\hline Neck mass and discharging opening together & $4(6.7)$ \\
\hline \multicolumn{2}{|l|}{ History of inflammation } \\
\hline Present & $27(45)$ \\
\hline Absent & $33(55)$ \\
\hline \multicolumn{2}{|l|}{ The location in relation to midline } \\
\hline Midline & $53(88.3)$ \\
\hline Off-midline & $7(11.7)$ \\
\hline \multicolumn{2}{|l|}{ The level in relation to hyoid bone } \\
\hline Juxtahyoid & $51(85)$ \\
\hline Infrahyoid & $7(11.7)$ \\
\hline Suprahyoid & $2(3.3)$ \\
\hline \multicolumn{2}{|l|}{ Complications of surgery } \\
\hline Subcutaneous seroma & $1(1.7)$ \\
\hline Subcutaneous hematoma & $1(1.7)$ \\
\hline Abscess formation & $1(1.7)$ \\
\hline Discharging sinus & $1(1.7)$ \\
\hline Unsatisfactory scars & $2(3.3)$ \\
\hline
\end{tabular}

The chief complaint was neck mass in $-49(81.6 \%)$ patients, discharging opening in seven $(11.7 \%)$ patients and both the neck mass and discharging opening together in four $(6.7 \%)$ patients. The duration of the main complaint was variable between 5 months and 16 years.

History of inflammation was detected in 27 (45\%) patients. In four $(6.7 \%)$ patients, this was followed by spontaneous rupture and fistula formation. Sixteen patients were treated by oral antibiotics; three patients were treated by aspiration and oral antibiotics. One $(1.6 \%)$ patient was subjected to incision and drainage elsewhere and developed fistula later.

Neck US was performed in all patients and detected the cyst and its location. Also, it assured that the thyroid gland was present in its normal location. One patient underwent CT scan. The mass or its opening was in the midline in 53 $(88.3 \%)$ patients and off-midline in seven $(11.7 \%)$ patients. The location of the mass or the opening was juxtahyoid in $51(85 \%)$ patients, infrahyoid in seven $(11.7 \%)$ patients, and suprahyoid in two $(3.3 \%)$ patients.

All patients were treated by the classical Sistrunk procedure. All patients received prophylactic antibiotic postoperatively, discharged $24 \mathrm{~h}$ postoperative, taking home medications in the form of oral antibiotics and nonsteroidal analgesics anti-inflammatory drugs. The first follow-up visit was on the fifth postoperative day wherein sutures are removed, and surgical site was evaluated.

Histopathological examination was done for all specimens and was consistent with TGDC. The diagnosis of TGDC was established by the detection of respiratory (pseudostratified ciliated columnar) and/or squamous epithelial lining associated with the thyroglossal tract or thyroid follicles in the surrounding stroma.

The follow-up ranged between 3 and 30 weeks with a mean of 18 weeks. Three cases had infected wound, presented fifth postoperative day and were treated successfully by oral antibiotics. There were one case of subcutaneous seroma and another case of subcutaneous hematoma, both treated by aspiration and antibiotics. One case of abscess formation required incision and drainage. One case of discharging sinus postoperatively, which improved with conservative management. Two patients had unsatisfactory scars which were revised 6 months later under local anesthesia with satisfactory outcome. Only one patient had recurrence and operated on 1 year later.

\section{DISCUSSION}

TGDC is the most prevalent midline cervical anomaly encountered in children $[4,18]$. Most TGDCs present during the first 5 years of life, although the lesion has repeatedly been detected during adulthood [19]. No gender predilection has been reported [20].

Out of 60 patients who were enrolled in this study, $45(75 \%)$ patients were children below 10 years, $11(18.3 \%)$ patients between 10 and 20 years, and four patients were above 20 years. The mean age at presentation in our cases was 11.18 years. Men were affected more than women in our study $(41: 19)$ which is in agreement with other studies [4]. 
Allard [4] indicated that most of the TGDCs were detected in the midline near the level of the hyoid bone. He found that $60 \%$ of TGDCs were located adjacent to the hyoid bone, 24\% were suprahyoid, $13 \%$ were between infrahyoid, and the remaining 3\% were intralingual. In this study, the location of the cyst or the fistula opening was adjacent to the hyoid bone in 51 $(85 \%)$ patients, infrahyoid in seven $(11.7 \%)$ patients, and suprahyoid in two (3.3\%) patients.

Owing to their anatomic association with the oral cavity, TGDCs are prone to infection [6]. Ostlie et al. [21] found that more than one-third of TGDC patients may present with a concomitant or past history of infection in the cyst. Inflammation and rupture are possible complications of TGDCs [21]. In the present study, $27(45 \%)$ patients had a history of inflammation, four $(6.7 \%)$ cases had spontaneous rupture of inflamed cyst forming fistula, and one (1.6\%) patient had abscess which drained surgically elsewhere and formed fistula also.

Radiological investigations for the detection of TGDC include US neck, which shows a cystic lesion. CT has a supplementary role; it accurately delineates the anatomy of the lesion, especially with large cysts [20]. Radioisotope study, thyroid scintigraphy, is done to document the presence of the normal functioning thyroid gland. Preoperative sonographic identification of a normal thyroid gland in patients with TGDC confirms the origin of the thyroid hormone and excludes ectopic thyroid [22].

In this study, a combination of clinical and radiological assessment resulted in diagnosing 100\% of cases of TGDC. CT neck was done once, in a patient with a large cyst to confirm the diagnosis. It was found that US was readily available, inexpensive, noninvasive, and did not involve ionizing radiation or use sedation, which is particularly important in children. Thus, thyroid scintigraphy was not essential if a normal thyroid gland was detected on routine preoperative US.

Literature reported that Sistrunk has reduced the recurrence from 50 to $3 \%$ [17]. Shah et al. [23] have found that the recurrence of TGDC remains low when the Sistrunk procedure is used regardless of the presenting age and symptomatology. In this study, there was only one (1.6\%) recurrent case out of 60 patients who underwent the Sistrunk procedure, which was in agreement with the results of the others [24]. Recurrence was attributed to inaccurate dissection, young age of the patient, and rupture of the cyst intraoperatively.

\section{CONCLUSION}

TGDC is the most common congenital cervical anomaly. Although it can be detected in all age groups, it was noted that there is maximum incidence in pediatric males. The study of the embryology of the hyroid gland and the anatomy of the neck is essential for understanding the management of TGDC. The diagnosis of TGDC in most instances is clinical. Combining the clinical examination and radiological investigations can improve the diagnosis. Meticulous dissection of TGDC and removal of the core of the hyoid bone is the key to successful surgery. Thus, the Sistrunk procedure, when carried out by experienced surgeon, decreases the recurrence of TGDCs to a very low rate.

\section{CONFLICT OF INTEREST}

There are no conflicts of interest.

\section{REFERENCES}

1. Mondin V, Ferlito A, Muzzi E, Silver CE, Fagan JJ, Devaney KO, et al. Thyroglossal duct cyst: personal experience and literature review. Auris Nasus Larynx 2008; 35:11-25.

2. Ewing C, Kornblut A, Greeley C, Manz H. Presentations of thyroglossal duct cysts in adults. Eur Arch Otorhinolaryngol 1999; 256:136-138.

3. Marshall SF, Becker WF. Thyroglossal cysts and sinuses. Ann Surg 1949; 129:642.

4. Allard RH. The thyroglossal cyst. Head Neck 1982; 5:134-146.

5. Baisakhiya N. Giant thyroglossal cyst in an elderly patient. Indian J Otolaryngol Head Neck Surg 2011; 63:27-28.

6. Telander RL, Filston HC. Review of head and neck lesions in infancy and childhood. Surg Clin North Am 1992; 72:1429-1447.

7. Clemente EI, Oyewumi M, Propst EJ, Ngan B-Y, Greer M-L. Thyroglossal duct cysts in children: sonographic features every radiologist should know and their histopathological correlation. Clin Imaging 2017; 46: 57-64.

8. Oyewumi M, Inarejos E, Greer ML, Hassouneh $\mathrm{B}$, Campisi P, Forte V, et al. Ultrasound to 
differentiate thyroglossal duct cysts and dermoid cysts in children. Laryngoscope $2015 ; 125$ :9981003.

9. Wadsworth D, Siegel MJ. Thyroglossal duct cysts: variability of sonographic findings. Am J Roentgenol 1994; 163:1475-1477.

10. Stern JS, Ginat DT, Nicholas JL, Ryan ME. Imaging of pediatric head and neck masses. Otolaryngol Clin North Am 2015; 48:225-246.

11. Gupta P, Maddalozzo J. Preoperative sonography in presumed thyroglossal duct cysts. Arch Otolaryngol Head Neck Surg 2001; 127:200-202.

12. Zander DA, Smoker WR. Imaging of ectopic thyroid tissue and thyroglossal duct cysts. Radiographics 2014; 34:37-50.

13. Ahuja AT, King AD, King W, Metreweli C. Thyroglossal duct cysts: sonographic appearances in adults. Am J Neuroradiol 1999; 20:579-582.

14. Edwards RM, Chapman T, Horn DL, Paladin AM, Iyer RS. Imaging of pediatric floor of mouth lesions. Pediatr Radiol 2013; 43:523-535.

15. Schlange H. Uber die Fustula colli congenital. Ach Klin Chir 1893; 46:390-392.

16. Sistrunk WE. The surgical treatment of cysts of the thyroglossal tract. Ann Surg 1920; 71:121.
17. Brown PM, Judd ES. Thyroglossal duct cysts and sinuses: results of radical (Sistrunk) operation. Am J Surg 1961; 102:494-501.

18. Moussatos GH, Baffes TG. Cervical masses in infants and children. Pediatrics 1963; 32:251-256.

19. Katz AD, Hachigian M. Thyroglossal duct cysts: a thirty year experience with emphasis on occurrence in older patients. Am J Surg 1988; 155:741-743.

20. Ahuja A, Wong K, King A, Yuen E. Imaging for thyroglossal duct cyst: the bare essentials. Clin Radiol 2005; 60:141-148.

21. Ostlie DJ, Burjonrappa SC, Snyder CL, Watts J, Murphy JP, Gittes GK, et al. Thyroglossal duct infections and surgical outcomes. J Pediatr Surg 2004; 39:396-399.

22. Tunkel DE, Domenech EE. Radioisotope scanning of the thyroid gland prior to thyroglossal duct cyst excision. Arch Otolaryngol Head Neck Surg 1998; 124:597-599.

23. Shah R, Gow K, Sobol SE. Outcome of thyroglossal duct cyst excision is independent of presenting age or symptomatology. Int $\mathrm{J}$ Pediatr Otorhinolaryngol 2007; 71:1731-1735.

24. Pelausa M, Forte V. Sistrunk revisited: a 10-year review of revision thyroglossal duct surgery at Toronto's Hospital for Sick Children. J Otolaryngol $1989 ; 18: 325-333$. 